\title{
EDUCATION FROM THE GENETIC POINT OF VIEW ${ }^{1}$
}

WILLIAM H. BURNHAM, PH.D.

Assistant Professor of Pedagogy, Clark University, Worcester, Mass.

The genetic conception of education is not new. The fundamental principle of genetic pedagogy - that of adaptation of education to the sequence of the stages of individual development - is at least as old as Comenius; but a point of view means nothing unless it enables one to see facts as well as to dream dreams. The result of modern child-study has been to give the insight that the only way to make this principle of adaptation vital is to find out by careful inductive study just what is the actual condition of children at different stages of growth and development. My purpose this morning is to recount some of the facts that have made the genetic point of view vital.

Fortunately, you are all familiar with the modern doctrines that education is a process; that the child is a different creature from the adult; that the child differs from the adolescent; that the child differs from the child at different stages of its development; that stages low and imperfect may be significant because preparatory to higher stages; that the child should be a child before he becomes a man; that the best guarantee of normal maturity is normal immaturity; that, as Froebel put it, the full and complete development of each stage is necessary for the development of succeeding stages; and again, on the social side, that the child is not so much fitting himself for society, but that he now is a member of society; that the school may represent society in embryo; that the teacher is primarily a member of this social group; that, as Professor Dewey puts it, the school life and the home life should be one and the same; that the purpose of the school is to introduce to the fundamental, constructive, productive

${ }^{1}$ Paper read before the Department of Child Study of the National Educational Association, Asbury Park, N. J., July 7, 1905. 
social activities; and that here, too, everything must be adapted to the child's own social experience.

Such familiar doctrines are based upon the genetic interpretation of facts. There are some other truths with which you are not perhaps so familiar. First of all, certain physiological facts.

Besides the obvious facts of growth and development which are of vital importance to education, there are certain more specific characteristics of the child's organism which are of practical importance. The child, for example, has a different circulatory system from the adult. The child's heart is relatively small, his arteries relatively large. During the period of development the heart grows very rapidly, and after adolescence it is relatively large, while the arteries are relatively small and narrow; or, more concretely, measurements have shown that during the period of growth the volume of the heart increases twelvefold, but the width of the aorta only threefold; or for $100 \mathrm{~cm}$. of height in case of the child the heart volume is $50 \mathrm{c.cm}$.; in case of the adult it is $150-190 \mathrm{c.cm}$. Thus during the school period there is a complete change of the circulatory type. This is a fact of great practical importance to be considered in all manual work and physical training, as well as in the ordinary work and play of the child. Cardiac disturbance is quickly compensated for in the child's organism in a way impossible with the adult; hence short and rather violent activity is quite harmless for the child, although prolonged activity and feats of endurance are dangerous.

Again, in case of the child the constituents of the blood are different from those of the adult; especially is the protection against contagion less in case of the child. In the child the blood is less alkaline, and thus offers less resistance to micro-organisms, the germ-destroying or bacteriacidal power of the serum, according to Weill, is not so great, and the white corpuscles of the blood with bacteriacidal power are less. In case of the adult they are estimated at 70 in 100 , but are only 28 at birth, 40 at the end of the first year, 54 in the third, 64 from the eighth to the tenth. That is, the protective power of the blood is twice as great in case of the adult as in case of the young child. This difference, together with the child's inferior protection in other ways, makes 
contagious diseases especially dangerous in the kindergarten and early primary grades. This is not a mere matter of theoretical speculation, but statistics show that 90 per cent. of all deaths from the common contagious diseases - such as measles, whoopingcough, and the like - occur before the age of ten; and an extensive study of measles in Munich shows that while between the years two and five the fatal cases were 5 per cent. of all, between the ages of six and ten, they were only 0.4 per cent. In other words, if an epidemic of measles occurs in the kindergarten, the chances are that four children in one hundred cases will die; if the epidemic can be postponed until the primary school, the chances are that only four in one thousand will die.

Another specially important difference between the child and the adult is in the activity of the lymph. This gives a child added protection from certain contagious diseases; but ${ }_{2}$ on the other hand, carries its own dangers with it. Experiments upon animals are instructive here. An artificial opening made into the thoracic duct of a young dog furnished lymph to the amount of between one-sixth and one-tenth of the body weight within one day, while from an adult dog lymph amounting to only one-tenth to one-sixteenth of the body weight was obtained. In the same way the lymph apparatus in the young child and adolescent is more active than in the adult.

Says Dr. Jacobi :

This is why the condition of the lymph glands in the young is of such importance. Whenever there is any infection of the mucous membrane, the infecting poison is carried off to the next gland, where there is a stoppingplace. That gland will become the seat of irritation or swelling. That is why .... whenever there is only a slight diarrhea, no matter from what cause, ... . lymph bodies in the neighborhood will swell. Unless such a diarrhea is soon stopped, the irritation will continue, congestion, inflammation, swelling of the glands will ensue, and the structure of these neighboring glands will be changed.

Other facts of practical significance are the different growthrates of different organs at different periods, the immaturity of special organs demanding special care, the undeveloped eyes of young children, the danger to the naso-pharynx, ear, and mouth from hypertrophied tonsils, and the like, the undeveloped voice 
of the child, and the strain especially upon boys at the period of mutation.

On the physical side, then, the aim of education from the genetic point of view is to give a child the opportunity for growth and development, and to foster the acquisition of habits of healthful activity. Many other things are desirable, but a child's first business is to grow. He may have another opportunity for the acquisition of knowledge, but the demands of development cannot wait.

On the mental side the contribution of genetic psychology and physiology is perhaps equally great, although it cannot be stated so concretely and definitely. As popularly believed, the child has less power of attention than the adult; contrary to popular opinion, he has also less memory power; but the chief differences may be summed up in one word - lack of experience.

The studies of children are in some important respects revolutionizing pedagogy. Attention is shifting from methods of teaching to methods of learning. The work has already passed from the stage of mere observation and crude speculation to the stage of analysis and experimentation. Concrete problems of school work and of economic and efficient methods of study are being investigated by careful methods in the laboratory. ${ }^{2}$ Meyer has studied the difference between the methods and results of school work done in a group of children,and similar work done by the children alone, finding that usually the group work is superior. Schmidt has studied the home work of children as compared with the school work and found, on the one hand, that in the more mechanical work pupils do better in the school because of the stimulation from other pupils, while in original essays in the mother-tongue and the like they do better in the isolation of the home. Meumann has studied the most economical and efficient methods of learning by heart. A single concrete example must suffice. Suppose the school task be to learn a stanza of a poem; children, as well as most adults, usually adopt the method of learning by parts - first a few words or a line, with many repetitions, and then another phrase or line. Is this a good method? Which is better - to learn the stanza as a whole, or to learn it

${ }^{2}$ See Archiv für die gesammte Psychologie, passim. 
by parts? By which method will it be learned in less time, with fewer repetitions, be remembered more permanently and accurately? Investigations upon many children, extending through several years, show clearly that, as a rule, with them as with adults, the method of learning as a whole is decidedly better. Somewhat less time is required by this method, a very much smaller number of repetitions suffices, and most important of all, confusion of association and possibility of error are lessened, while correct and healthful habits of association and of study are developed.

Such are some of the facts as I understand them; we have in the child a psycho-physical organism, unstable, immature, growing and developing irregularly at different periods and at different rates in different parts and organs. These are facts of the utmost practical importance in the everyday work of the school. But, while we are primarily concerned with such concrete facts, we may stop for a moment to glance at the wider relations of these facts. Modern biological study has enormously enlarged the genetic conception of education. It is hardly fanciful to draw an analogy between the adjustment of the individual that we call education and the adaptation and mutation of species in plants found by De Vries and others. And if this investigator is right in concluding that when a species is in the period of mutation, as he found the evening primrose, new species are easily formed, and, after this period is passed, new species cannot be formed, then something similar seems to be true of the individual. Without pushing the analogy too far, in general it seems to be true that during the nascent period new acquisitions and adaptations can easily be made. After the nascent period is passed, new acquisitions are made only with great difficulty or not at all. The great lesson is one that teachers and parents are slow to learn - that nature works by times and seasons. We cannot forestall her without danger. We cannot let the moment of opportunity pass without irrevocable loss. Perhaps each organ has its nascent period when the conditions are most favorable for the acquisition of function, and the skill of the educator is put to its greatest test in determining when the favorable opportunity for training occurs. 
When one says that hygiene and sound pedagogy fear premature and unrelated developments, and that the best guarantee of normal maturity is normal immaturity, it means very little; but when one studies the developing nervous system of young animals, all this becomes very concrete and emphatic. I know of no more interesting illustration of this than the studies of the guinea pig, made by Miss Allen. The guinea pig develops rapidly, and it is mentally precocious at a very early age. The white rat, on the other hand, develops relatively slowly. At birth the guinea pig has all its senses, pretty well-developed muscles, and is psychically mature at the age of three or four days. The white rat at birth, on the other hand, is undeveloped, blind, deaf, naked, his nervous system unmedullated, his muscular system without control. He does not gain the power of vision for sixteen or seventeen days, of hearing for perhaps thirteen days, nor become psychically mature for from twenty-four to twenty-seven days. The result of the precocious development of the guinea pig as compared with the slower development of the white rat appears in the education of the two animals.

As Miss Allen puts it:

When the guinea pig has forced his way through a labyrinth, he has reached the end of his psychical powers. He cannot pull a latch nor push a bolt; he will not depress an inclined plane, chew a string, nor stamp his foot. ... . The experience of the white rat extends to strange combinations of wires and springs, and all the delightful surprises revealed by secret doors; but when the guinea pig has turned the proper number of corners, his dinner must be waiting for him or he does not get it. The white rat at three days is just learning to crawl, has never seen an object, and remembers nothing. The guinea pig at that age has triumphantly recalled a complex path, at the end of which he sits eating his well-deserved carrot. At twenty-three days the rat is lifting latches neatly and forming what Hobhouse calls "practical judgments" as to the value of an inclined plane, in a situation at the center of which is his food - a desired thing, an end. The guinea pig is still wearing out the floor of the same labyrinth.

And, again, to quote Miss Allen:

The contrasting features in the two animals are their nervous systems. In the one a mature nervous system is accompanied by psychical maturity; in the other, neural immaturity permits great psychical development.

If more were needed to show the importance of the genetic point of view, the errors that result from the lack of it would be 
enough. I have time for but a single illustration. In medicine and hygiene there is always danger, if one lacks the genetic point of view, of treating the diseases incidental to growth and development, especially the nervous diseases - neuroses of development as they are technically called - in the same way that one would traet similar diseases in adults. In a word, there is danger of mistaking incidents of development for neuroses of degeneration. A concrete case in point has recently come to my attention.

An hysterical boy of fifteen was committed to a hospital. It was found that he had certain cardiac symptoms, precordial pain, and the like; and the physician to whom the boy's case was allotted, apparently having had more experience with old men than with children, treated him by giving one-hundredth of a grain of nitroglycerin three times a day. The probability is that the boy's heart will be injured for life; whereas with care, and a judicious use of iron and other tonics, the boy would have outgrown the cardiac trouble along with his hysteria. Such treatment of an adolescent is so atrocious that it is hardly credible that any reputable physician could be guilty of such an error. Apparently it was a case of mistaking a neurosis of development for a disease of adult life, on account of lack of the genetic point of view.

Teachers, as a result of their special work, are very likely to fall into similar errors. The defects and even the wickedness of children and youth, usually mere psychoses of development, are often taken too seriously by both teachers and parents, and the error of mistaking a psychosis of development for a sign of degeneracy is perhaps no less serious than that of a physician who gives nitroglycerin to the adolescent. If child-study had done no more than to give teachers the genetic point of view, all the labor expended would be well repaid; for here they are prone to err. If they do not adopt the nitroglycerin method of discipline, they are apt to desire a guinea-pig form of prematurity.

Everywhere today teachers and students are studying children; some in the laboratory with carefully controlled conditions; some by the questionnaire method-la méthode démocratique, as the French call it; others by mere observation and reminiscence, often by methods crude and unreliable. What is the result 
of all this? What does it all amount to? Some of this work has yielded practical results. Some of it has illustrated the genetic point of view. All, I believe, has been valuable. For a single illustration, in the city where I live, the students of the normal school observe children as they have opportunity, and record isolated facts, sometimes the significant, more often the trivial and banal. There are tens of thousands of such reports in the archives of the school. Each year adds something to this store. Is that all? By no means. The students in this work acquire the genetic point of view, the right attitude toward children; and Principal Russell says that reports from graduates are to the effect that the bad boys and the defective become objects of special interest and study.

It is difficult to describe a point of view, but the point of view is everything. It determines what we see and what we are unable to see. In every profession, especially perhaps in the teacher's calling, the development of the professional point of view soon inevitably makes it impossible for one to see things as they really are. The attainment of the genetic point of view would save teachers from much of this scholastic blindness. It would save them from worry over defects and imperfections, and give the insight that education is a process, and that normal development implies imperfection and the gradual approximation to higher stages and higher ideals. It would revolutionize the teacher's calling, and the teacher's task would become a part of the great world-process of evolution in human life and human society. Again, it would save the school from what Professor James calls "the modern textbook of Moloch, in whose belly the souls of living children are turned to ashes," and from the mechanism of artificiality and traditional examination, classification, and grading. It would emancipate them from the idolatry of methods. It would save them from overstimulation and overpressure, and from that overstraining which means arrest of development. In a word, it would make the aim of the modern school development, health, individualization, and the opportunity for spontaneous intercourse with nature and society. 